Braz J Med Biol Res, January 2012, Volume 45(1) 33-37

doi: 10.1590/S0100-879X2011007500153

Effects of simultaneous exposure to stress and nicotine on nicotineinduced locomotor activation in adolescent and adult rats

A. Zago, R.M. Leão, P.E. Carneiro-de-Oliveira, M.T. Marin, F.C. Cruz and C.S. Planeta

The Brazilian Journal of Medical and Biological Research is partially financed by

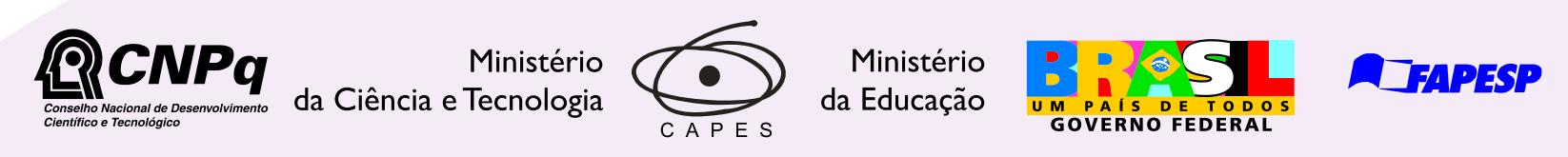

Institutional Sponsors
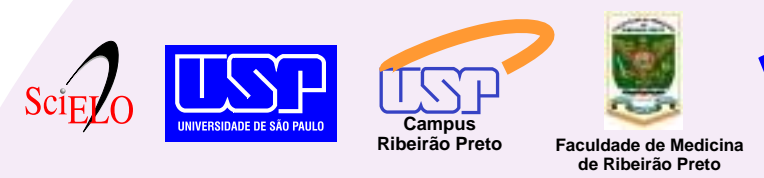

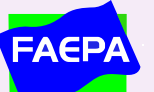
HCFMRP

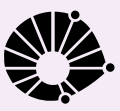

UNICAMP shimadzu
A디담

Associação
Fundo Associo
de Incentivo
à Pesquisa à Pesquisa

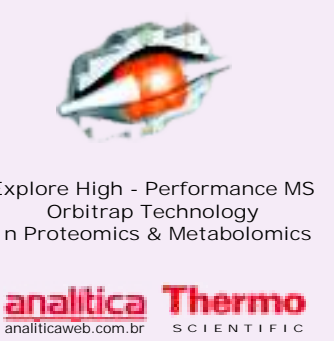




\title{
Effects of simultaneous exposure to stress and nicotine on nicotine-induced locomotor activation in adolescent and adult rats
}

\author{
A. Zago ${ }^{1}$, R.M. Leão ${ }^{1,2}$, P.E. Carneiro-de-Oliveira ${ }^{1,2}$, M.T. Marin'1, \\ F.C. Cruz ${ }^{1}$ and C.S. Planeta ${ }^{1,2}$ \\ ${ }^{1}$ Laboratório de Farmacologia, Faculdade de Ciências Farmacêuticas, \\ Universidade Estadual Paulista, Araraquara, SP, Brasil \\ ${ }^{2}$ Programa Interinstitucional de Pós-Graduação em Ciências Fisiológicas, \\ Universidade Federal de São Carlos/Universidade Estadual de São Paulo, Araraquara, SP, Brasil
}

\begin{abstract}
Preclinical studies have shown that repeated stress experiences can result in an increase in the locomotor response to the subsequent administration of drugs of abuse, a phenomenon that has been termed behavioral cross-sensitization. Behavioral sensitization reflects neuroadaptive processes associated with drug addiction and drug-induced psychosis. Although crosssensitization between stress- and drug-induced locomotor activity has been clearly demonstrated in adult rats, few studies have evaluated this phenomenon in adolescent rats. In the present study, we determined if the simultaneous exposure to stress and nicotine was capable of inducing behavioral sensitization to nicotine in adolescent and adult rats. To this end, adolescent (postnatal day (P) 28-37) and adult (P60-67) rats received nicotine $(0.4 \mathrm{mg} / \mathrm{kg}, s c)$ or saline $(0.9 \% \mathrm{NaCl}, s c)$ and were immediately subjected to restraint stress for $2 \mathrm{~h}$ once a day for 7 days. The control group for stress was undisturbed following nicotine or saline injections. Three days after the last exposure to stress and nicotine, rats were challenged with a single dose of nicotine $(0.4 \mathrm{mg} / \mathrm{kg}, \mathrm{sc})$ or saline and nicotine-induced locomotion was then recorded for $30 \mathrm{~min}$. In adolescent rats, nicotine caused behavioral sensitization only in animals that were simultaneously exposed to stress, while in adult rats nicotine promoted sensitization independently of stress exposure. These findings demonstrate that adolescent rats are more vulnerable to the effects of stress on behavioral sensitization to nicotine than adult rats.
\end{abstract}

Key words: Cross-sensitization; Locomotor activity; Nicotine; Stress; Adolescence

\section{Introduction}

Drug abuse most commonly begins during adolescence, a period of ontogeny during which individuals exhibit agespecific behavioral characteristics, such as risk taking and novelty seeking, which could predispose them to initiate drug use $(1,2)$. As observed for other drugs of abuse, it has been demonstrated that the initiation of tobacco smoking occurs during early adolescence (3). Many studies have shown that tobacco use during adolescence produces enduring effects that may increase the vulnerability to addiction later in life $(4,5)$. Moreover, pre-clinical evidence shows that nicotine is more rewarding and less aversive during adolescence than during adulthood $(6,7)$.

In animals, repeated administration of drugs of abuse may result in a gradual increase of the motor stimulant re- sponse with each subsequent injection. This phenomenon is termed behavioral sensitization, which is suggested to reflect neuroadaptive processes associated with drug addiction (810) and drug-induced psychosis (11). Despite the variability observed in the acute effects of nicotine on locomotor activity, repeated administration of this drug induces behavioral sensitization in adult rats (12-15). Although adolescent rats, as compared to adults, were more sensitive to the acute effect of nicotine on locomotor activity $(8,16)$, they did not express behavioral sensitization to nicotine after repeated administration of this substance $(13,14,17)$.

Exposure to stress appears to increase the number of cigarettes smoked and is strongly associated with craving and relapse of tobacco smoking $(18,19)$. Preclinical studies

Correspondence: C.S. Planeta, Laboratório de Farmacologia, Faculdade de Ciências Farmacêuticas, UNESP, Rod. Araraquara-Jaú, km 1, 14801-902 Araraquara, SP, Brasil. Fax: +55-16-3301-6980. E-mail: cplaneta@fcfar.unesp.br

Received July 20, 2011. Accepted October 24, 2011. Available online November 18, 2011. Published January 16, 2012. 
have shown that repeated stress experiences can result in an increase in the locomotor response to subsequent administration of drugs, a phenomenon that has been termed behavioral cross-sensitization (20-27). For instance, cross-sensitization between stress and psychostimulants has been observed after repeated exposure to footshock $(28,29)$, restraint $(30)$, food restriction (31), and social defeat stress $(8,32)$.

The results regarding stress-promoting cross-sensitization to nicotine in adult rats are very contradictory. For example, Kita et al. (33) demonstrated that in adult rats repeated exposure to social stress enhanced nicotineinduced behavioral sensitization, whereas Faraday et al. (34) failed to observe changes in the locomotor response to nicotine administered with mini-pumps in rats exposed to restraint stress. Moreover, a study from our laboratory showed that previous exposure to restraint stress for 7 days did not affect nicotine-induced locomotor-activating effects in adult and adolescent rats (14).

Despite the strong influence of stress on tobacco addiction, the effects of simultaneous exposure to repeated stress and nicotine on nicotine-induced behavioral sensitization have not been investigated. Thus, the objective of the present study was to examine the effects of simultaneous exposure to stress and nicotine on nicotine-induced behavioral sensitization in adolescent and adult rats.

\section{Subjects and Methods}

\section{Subjects}

Male Wistar rats were obtained from the animal breeding facility of Universidade Estadual Paulista (UNESP, Botucatu, SP, Brazil) immediately after weaning, on postnatal day $(P)$ 21 . Animals were housed in $32-\mathrm{cm}$ wide $\times 40-\mathrm{cm}$ long $\times 16-$ $\mathrm{cm}$ high plastic cages (4 animals/cage) in a room maintained at $23 \pm 2^{\circ} \mathrm{C}$ on a $12: 12$-h light/dark cycle (lights on at 7:00 am) and were allowed free access to food and water. All experiments were performed during the light phase. Each animal was used only in one experimental procedure. The experiments were carried out between 8:00 and 12:00 h.

Adolescence was defined, according to Spear (2), as the age period between P28 and P42. Experiments were started on P28 for adolescent rats and on P60 for adult rats.

The experimental protocol was approved by the Ethics Committee for Use of Human or Animal Subjects of Faculdade de Ciências Farmacêuticas, UNESP (CEP-24/2003) and the experiments were conducted according to the ethical principles of the Brazilian College of Animal Experimentation (COBEA), based on NIH Guidelines for the Care and Use of Laboratory Animals.

\section{Drug}

Nicotine $^{\circledR}$ (Sigma, USA) was diluted in saline $(0.9 \%$ $\mathrm{NaCl}), \mathrm{pH} 7.0$.

\section{Apparatus}

Behavioral testing was conducted in commercially available (Columbus Instruments, USA) activity-monitoring chambers consisting of $40-\mathrm{cm}$ wide $\times 40-\mathrm{cm}$ long and $16-\mathrm{cm}$ high Plexiglas cages. The chambers contained 10 pairs of photocell beams, which were used to measure the horizontal locomotor activity. The consecutive interruption of two beams was recorded as one locomotion unit.

\section{Nicotine- and stress-induced behavioral sensitization}

The entire sensitization protocol took 10 days. On days 1 to 7 , rats were weighed and given sc injections of nicotine $(0.4 \mathrm{mg} / \mathrm{kg})$ or saline once a day and immediately subjected to restraint stress for $2 \mathrm{~h}$. The control animals were undisturbed in their home cages after the injections of nicotine or saline. On days 8 and 9 the animals did not receive any treatment.

On day 10 animals were allowed a 20-min adaptation period to the photocell apparatus and were then immediately injected with a challenge dose of saline (adolescents: nonstress, $\mathrm{N}=13$; chronic stress, $\mathrm{N}=12$; adults: non-stress, $\mathrm{N}=14$; chronic stress, $\mathrm{N}=12)$ or nicotine $(0.4 \mathrm{mg} / \mathrm{kg}, \mathrm{sc})$ (adolescents: non-stress, $\mathrm{N}=14$; chronic restraint, $\mathrm{N}=13$; adults: non-stress, $N=14$; chronic restraint, $N=13$ ). Immediately after the injections, the animals were returned to the activity chambers and their locomotor activity was recorded during a 30-min testing session as described above.

Adolescent and adult rats were on P37 and P69, respectively, when the behavioral tests were performed.

\section{Statistical analysis}

All data are reported as means \pm SEM. Levine's tests for homogeneity of variance performed for the behavioral data showed no statistically significant differences, indicating homogeneity of variance. Thus, locomotor activity data for both adolescent and adult rats were analyzed by $2 \mathrm{x}$ $2 \times 2$ ANOVA [drug treatment (nicotine vs saline) $x$ stress (stress vs non-stress) $\mathrm{x}$ challenge (nicotine vs saline)]. When a significant $(P<0.05)$ main effect was observed, the Newman-Keuls test was used for post hoc comparisons.

\section{Results}

\section{Adolescent rats}

Three-way ANOVA showed significant differences regarding drug treatment $[F(1,44)=11.13 ; P<0.005]$, challenge $[F(1,44)=45.42 ; P<0.001]$, but not stress $[F(1,44)=$ $0.08 ; P=0.78]$ factors. In addition, a significant interaction was detected between the three factors $[F(1,44)=5.85$; $P$ $<0.05$ ] (Figure 1).

Considering the control groups, further analysis (Newman-Keuls test) revealed that nicotine increased locomotor activity in rats pretreated with saline (SAL) or nicotine (NIC). However, no significant difference was observed between the SAL+NIC and NIC+NIC groups, indicating that pretreat- 
ment with nicotine did not cause locomotor sensitization.

For the stress groups, further analysis (Newman-Keuls test) revealed that nicotine increased locomotor activity in rats pretreated with saline or nicotine. In addition, the locomotor response to a nicotine challenge was higher in the NIC+NIC group when compared to the SAL+NIC group, indicating that pretreatment with nicotine caused locomotor sensitization in animals simultaneously exposed to stress and nicotine.

\section{Adult rats}

Three-way ANOVA revealed significant differences in nicotine-induced locomotion considering treatment $[F(1,45)$ $=33.95 ; \mathrm{P}<0.001]$ and challenge factors $[F(1,45)=$ 50.57; $P<0.001]$ but not stress $[F(1,45)=0.36 ; P=0.55]$. Furthermore, a significant interaction between treatment and challenge factors was detected $[F(1,45)=22.12 ; \mathrm{P}<$ 0.001] (Figure 2).

For both the control and stress groups, the NewmanKeuls test revealed that nicotine challenge significantly increased locomotor activity only in animals pretreated with nicotine $(P<0.01)$, showing that pretreatment with nicotine caused locomotor sensitization to nicotine independently of stress.

No significant difference in nicotine challenge effect was found between rats repeatedly exposed to restraint stress and the non-stress group $(P>0.05)$.

\section{Discussion}

In adolescent rats, we observed that nicotine caused behavioral sensitization only in animals that were simultaneously exposed to stress, while in adult rats nicotine promoted sensitization in both the stress and control groups. These data are the first to demonstrate the effects of repeated and simultaneous exposure to stress and nicotine on the locomotor response to this drug.

The observation that repeated nicotine administration did not induce locomotor sensitization in adolescent rats corroborates findings demonstrating that repeated treatment with nicotine $(0.4 \mathrm{mg} / \mathrm{kg})$ during adolescence did not induce behavioral sensitization $(13,14,17)$. Moreover, data from our laboratory demonstrated that the previous exposure to stress was not able to change the locomotor response to a subsequent injection of nicotine in male adolescent rats (22). Additionally, McCormick and Ibrahim (35) showed that 1-h isolation had no effect on nicotineinduced locomotor activity in adolescent rats. However, in the present study, when adolescent rats received nicotine and were immediately exposed to stress, they showed a clear-cut sensitization of locomotor activity. Taken together, these results suggest that simultaneous exposure to nicotine and stress is necessary for the development of behavioral sensitization to this drug in adolescent rats.

Compared to studies that used previous exposure to

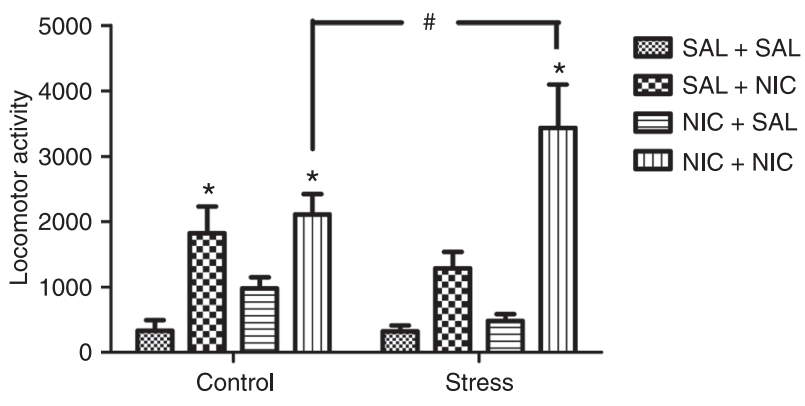

Figure 1. Effect of simultaneous exposure to stress and nicotine on locomotor activity in response to a nicotine injection in adolescent rats. $\mathrm{SAL}=0.9 \% \mathrm{NaCl} ; \mathrm{NIC}=$ nicotine. ${ }^{*} \mathrm{P}<0.05$ compared to all other groups; ${ }^{\# P}<0.05$ compared to $\mathrm{NIC}+\mathrm{NIC}$ control group (Newman-Keuls test).

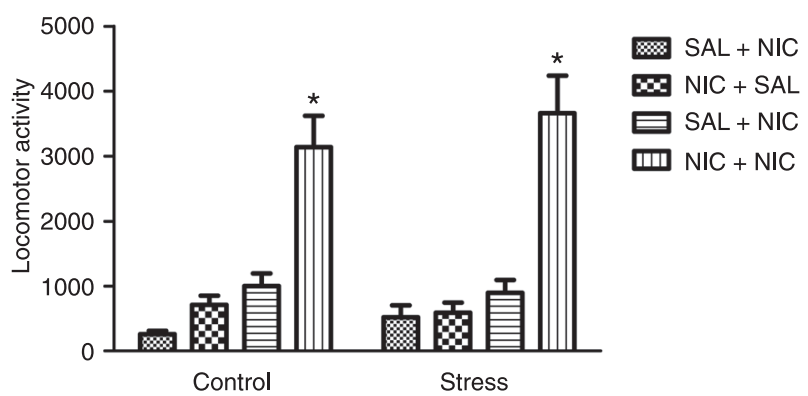

Figure 2. Effect of simultaneous exposure to stress and nicotine on locomotor activity in response to a nicotine injection in adult rats. $\mathrm{SAL}=0.9 \% \mathrm{NaCl} ; \mathrm{NIC}=$ nicotine. ${ }^{*} \mathrm{P}<0.05$, compared to all other groups (Newman-Keuls test).

stress to evaluate the cross-sensitization to nicotine $(22,35)$, our experimental design (simultaneous exposure to stress and nicotine) appears to be more predictive of the human situation, in which stress and drug use are concomitant $(18,19)$.

The repeated administration of nicotine to adult rats induced behavioral sensitization in both the stress and non-stress (control) groups. These findings also agree with other reports describing that repeated nicotine treatment causes behavioral sensitization in adult rats (12-14,36). Moreover, the fact that stress did not induce cross-sensitization to nicotine corroborates previous reports showing that pre-exposure to restraint stress did not change the effects of nicotine on locomotor activity $(14,34)$. On the other hand, it was demonstrated that rats exposed to psychological stress for 10 days (by being exposed to the emotional responses of animals that received foot-shock) were sensitized to nicotine-induced ambulatory stimulation (33). Stress-induced cross-sensitization to nicotine in adult animals remains controversial and seems to depend on the 
intensity, duration, frequency and timing of stress exposure. In our study, we also observed that stress did not increase the locomotor sensitization that was induced by repeated nicotine administration. This fact may have been due to a ceiling effect of nicotine-induced locomotor sensitization at the dose $0.4 \mathrm{mg} / \mathrm{kg}$. Future studies using lower doses will be carried out in our laboratory.

Since animals were tested in a novel environment, we cannot rule out that stress-induced changes in the response to novelty may interfere with the measurement of the stimulant effects of nicotine. Previous data from our laboratory have shown that adult rats exposed to 14 days of repeated restraint stress showed an increased locomotor response to novelty and sensitization to cocaine-induced locomotor activity (21). However, in adolescent rats the exposure to both chronic restraint and variable stress increased cocaineinduced locomotion, but did not change the response to a novel environment (37).

These results suggest that stress-induced changes in the locomotor response to novelty are not related to the cross-sensitization between stress and drugs, at least in adolescent animals.

Since behavioral sensitization reflects neuroadaptive processes associated with drug addiction (9), our results suggest that simultaneous exposure to stress and nicotine might enhance the addictive properties of nicotine in adolescent rats.

Age-related differences in response to psychostimulants following exposure to stress have also been reported. For instance, it was demonstrated that restraint stress caused cross-sensitization to cocaine in adolescent, but not in adult rats $(21,38)$.

Most available evidence suggests a critical role for the hypothalamus-pituitary-adrenal (HPA) axis in drug-induced

\section{References}

1. Izenwasser S, French D. Tolerance and sensitization to the locomotor-activating effects of cocaine are mediated via independent mechanisms. Pharmacol Biochem Behav 2002; 73: 877-882.

2. Spear LP. The adolescent brain and age-related behavioral manifestations. Neurosci Biobehav Rev 2000; 24: 417463.

3. Chen K, Kandel DB. The natural history of drug use from adolescence to the mid-thirties in a general population sample. Am J Public Health 1995; 85: 41-47.

4. Breslau N, Peterson EL. Smoking cessation in young adults: age at initiation of cigarette smoking and other suspected influences. Am J Public Health 1996; 86: 214-220.

5. Chen J, Millar WJ. Age of smoking initiation: implications for quitting. Health Rep 1998; 9: 39-46.

6. Adriani W, Deroche-Gamonet V, Le Moal M, Laviola G, Piazza PV. Preexposure during or following adolescence differently affects nicotine-rewarding properties in adult rats. Psychopharmacology 2006; 184: 382-390. sensitization $(23,38)$. Concerning nicotine, Johnson et al. (39) showed that adrenalectomy disrupted the development, but not the expression, of sensitization, since it had no effect if performed in rats already sensitized. Taking these observations together, we could suppose that differences in the adaptation of HPA activity to stress between adult and adolescent rats could explain, at least in part, the results obtained in the present study. However, more investigations are necessary to characterize this relationship.

In rodents, these adaptations have been mainly monitored by comparing corticosterone levels in response to stress in adult and adolescent rats. For example, in adult rats when the same stressor is repeated the HPA response can desensitize or remain unchanged (for a review, see Ref. 40). Conversely, previous results from our laboratory have shown that exposure to repeated restraint stress during adolescence did not modify the HPA axis response to a new exposure to restraint stress (Cruz FC, Marin MT, Leão RM, Planeta CS, unpublished data), suggesting that adolescent rats are resistant to neuroendocrine adaptation to stressors compared to adult rats.

Overall, our results suggest that adolescents are more susceptible to stress influence on the development of nicotine addiction.

\section{Acknowledgments}

The authors appreciate the excellent technical assistance of Elisabete Zocal Paro Lepera and Rosana Finoti Pupim Silva (from Faculdade de Ciências Farmacêuticas, UNESP) and FAPESP. Research supported by PADC Faculdade de Ciências Farmacêuticas, UNESP (\#01/11880-4). C.S. Planeta is the recipient of a CNPq research fellowship.

7. O'Dell LE, Bruijnzeel AW, Smith RT, Parsons LH, Merves ML, Goldberger BA, et al. Diminished nicotine withdrawal in adolescent rats: implications for vulnerability to addiction. Psychopharmacology 2006; 186: 612-619.

8. Covington HE III, Miczek KA. Repeated social-defeat stress, cocaine or morphine. Effects on behavioral sensitization and intravenous cocaine self-administration "binges". Psychopharmacology 2001; 158: 388-398.

9. Robinson TE, Berridge KC. The neural basis of drug craving: an incentive-sensitization theory of addiction. Brain Res Brain Res Rev 1993; 18: 247-291.

10. Robinson TE, Berridge KC. Review. The incentive sensitization theory of addiction: some current issues. Philos Trans $R$ Soc Lond B Biol Sci 2008; 363: 3137-3146.

11. Robinson TE, Becker JB. Enduring changes in brain and behavior produced by chronic amphetamine administration: a review and evaluation of animal models of amphetamine psychosis. Brain Res 1986; 396: 157-198.

12. Booze RM, Welch MA, Wood ML, Billings KA, Apple SR, 
Mactutus CF. Behavioral sensitization following repeated intravenous nicotine administration: gender differences and gonadal hormones. Pharmacol Biochem Behav 1999; 64: 827-839.

13. Collins SL, Izenwasser S. Chronic nicotine differentially alters cocaine-induced locomotor activity in adolescent vs adult male and female rats. Neuropharmacology 2004; 46: 349-362.

14. Cruz FC, Delucia R, Planeta CS. Differential behavioral and neuroendocrine effects of repeated nicotine in adolescent and adult rats. Pharmacol Biochem Behav 2005; 80: 411417.

15. Faraday MM, Blakeman KH, Grunberg NE. Strain and sex alter effects of stress and nicotine on feeding, body weight, and HPA axis hormones. Pharmacol Biochem Behav 2005; 80: 577-589.

16. Faraday MM, Elliott BM, Grunberg NE. Adult vs adolescent rats differ in biobehavioral responses to chronic nicotine administration. Pharmacol Biochem Behav 2001; 70: 475489.

17. Santos GC, Marin MT, Cruz FC, Delucia R, Planeta CS. Amphetamine- and nicotine-induced cross-sensitization in adolescent rats persists until adulthood. Addict Biol 2009; 14: $270-275$

18. Cohen S, Lichtenstein E. Perceived stress, quitting smoking, and smoking relapse. Health Psychol 1990; 9: 466-478.

19. Niaura R, Abrams DB. Smoking cessation: progress, priorities, and prospectus. J Consult Clin Psychol 2002; 70: 494509.

20. Antelman SM, Eichler AJ, Black CA, Kocan D. Interchangeability of stress and amphetamine in sensitization. Science 1980; 207: 329-331.

21. Araujo AP, Delucia R, Scavone C, Planeta CS. Repeated predictable or unpredictable stress: effects on cocaineinduced locomotion and cyclic AMP-dependent protein kinase activity. Behav Brain Res 2003; 139: 75-81.

22. Cruz FC, Delucia R, Planeta CS. Effects of chronic stress on nicotine-induced locomotor activity and corticosterone release in adult and adolescent rats. Addict Biol 2008; 13: 63-69.

23. Deroche V, Piazza PV, Casolini P, Maccari S, Le Moal M, Simon $\mathrm{H}$. Stress-induced sensitization to amphetamine and morphine psychomotor effects depend on stress-induced corticosterone secretion. Brain Res 1992; 598: 343-348.

24. Haile CN, GrandPre T, Kosten TA. Chronic unpredictable stress, but not chronic predictable stress, enhances the sensitivity to the behavioral effects of cocaine in rats. Psychopharmacology 2001; 154: 213-220.

25. Herman JP, Stinus L, Le Moal M. Repeated stress increases locomotor response to amphetamine. Psychopharmacology 1984; 84: 431-435.

26. Nikulina EM, Covington HE III, Ganschow L, Hammer RP $\mathrm{Jr}$, Miczek KA. Long-term behavioral and neuronal crosssensitization to amphetamine induced by repeated brief social defeat stress: Fos in the ventral tegmental area and amygdala. Neuroscience 2004; 123: 857-865.

27. Reid MS, Ho LB, Tolliver BK, Wolkowitz OM, Berger SP. Partial reversal of stress-induced behavioral sensitization to amphetamine following metyrapone treatment. Brain Res 1998; 783: 133-142.

28. Kalivas PW, Duffy P. Similar effects of daily cocaine and stress on mesocorticolimbic dopamine neurotransmission in the rat. Biol Psychiatry 1989; 25: 913-928.

29. Sorg BA, Kalivas PW. Effects of cocaine and footshock stress on extracellular dopamine levels in the ventral striatum. Brain Res 1991; 559: 29-36.

30. Hahn B, Zacharko RM, Anisman H. Alterations of amphetamine elicited perseveration and locomotor excitation following acute and repeated stressor application. Pharmacol Biochem Behav 1986; 25: 29-33.

31. Cabib S, Orsini C, Le Moal M, Piazza PV. Abolition and reversal of strain differences in behavioral responses to drugs of abuse after a brief experience. Science 2000; 289: 463-465.

32. Yap JJ, Miczek KA. Social defeat stress, sensitization, and intravenous cocaine self-administration in mice. Psychopharmacology 2007; 192: 261-273.

33. Kita T, Okamoto M, Kubo K, Tanaka T, Nakashima T. Enhancement of sensitization to nicotine-induced ambulatory stimulation by psychological stress in rats. Prog Neuropsychopharmacol Biol Psychiatry 1999; 23: 893-903.

34. Faraday MM, Elliott BM, Phillips JM, Grunberg NE. Adolescent and adult male rats differ in sensitivity to nicotine's activity effects. Pharmacol Biochem Behav 2003; 74: 917-931.

35. McCormick CM, Ibrahim FN. Locomotor activity to nicotine and Fos immunoreactivity in the paraventricular nucleus of the hypothalamus in adolescent socially-stressed rats. Pharmacol Biochem Behav 2007; 86: 92-102.

36. Ericson M, Norrsjo G, Svensson Al. Behavioral sensitization to nicotine in female and male rats. J Neural Transm 2010; 117: 1033-1039.

37. Lepsch LB, Gonzalo LA, Magro FJ, Delucia R, Scavone C, Planeta CS. Exposure to chronic stress increases the locomotor response to cocaine and the basal levels of corticosterone in adolescent rats. Addict Biol 2005; 10: 251-256.

38. Marinelli M, Rouge-Pont F, Deroche V, Barrot M, De JesusOliveira C, Le Moal M, et al. Glucocorticoids and behavioral effects of psychostimulants. I: locomotor response to cocaine depends on basal levels of glucocorticoids. J Pharmacol Exp Ther 1997; 281: 1392-1400.

39. Johnson DH, Svensson AI, Engel JA, Soderpalm B. Induction but not expression of behavioural sensitization to nicotine in the rat is dependent on glucocorticoids. Eur $J$ Pharmacol 1995; 276: 155-164.

40. Aguilera G. Corticotropin releasing hormone, receptor regulation and the stress response. Trends Endocrinol Metab 1998; 9: 329-336. 